\title{
Mitochondrial DNA D-loop lesions with the enhancement of DNA repair contribute to gastrointestinal cancer progression
}

\author{
BISHI WANG ${ }^{1 *}$, LUXIN QIAO ${ }^{2 *}$, YUHE WANG $^{3 *}$, JING ZENG $^{2}$, DEXI CHEN $^{2}$, \\ HONGLIANG GUO ${ }^{1}$ and YULIN ZHANG ${ }^{2}$
}

\author{
${ }^{1}$ Department of General Surgery, Shandong Cancer Hospital Affiliated to Shandong University, \\ Shandong Academy of Medical Sciences, Jinan, Shandong 250117; ${ }^{2}$ Department of Infectious Diseases, \\ Capital Medical University Affiliated Beijing You An Hospital, Beijing Institute of Hepatology, Beijing 100069; \\ ${ }^{3}$ Department of General Surgery, Changping District Hospital, Capital Medical University, Beijing 102200, P.R. China
}

Received January 21, 2018; Accepted September 4, 2018

DOI: $10.3892 /$ or.2018.6724

\begin{abstract}
Gastrointestinal cancer (GIC) is a worldwide public health problem with a high mortality rate. Mitochondrial DNA (mtDNA) mutations in the displacement loop (D-loop) region are quite common in various types of primary human cancers; however, their role in the pathogenesis of GIC is controversial. In the present study, tumor and para-tumor tissues were selected from 18 patients with gastric cancer (GC), 21 patients with colon cancer (CC) and 30 patients with rectal cancer (RC). The mtDNA D-loop was analyzed by sequencing and reverse transcription-quantitative polymerase chain reaction. Furthermore, DNA oxidative damage and DNA repair functioning were detected by immunohistochemistry. The results demonstrated that increased mtDNA deletion was not evident in GIC; however, significant DNA oxidative damage was significant in $\mathrm{RC}$ by detecting 8-hydroxyguanine expression. In addition, over-activated DNA repair was identified in $\mathrm{CC}$ and $\mathrm{RC}$ through the detection of 8-oxo-20-deoxyguanosine glycosylase 1 expression. The mtDNA D-loop had a specific mutation hotspot region, and the level of mtDNA D-loop mutations was correlated with the progression of the GIC.
\end{abstract}

Correspondence to: Dr Yulin Zhang, Department of Infectious Diseases, Capital Medical University Affiliated Beijing You An Hospital, Beijing Institute of Hepatology, 8 Xi TouTiao, You An Men Wai, Beijing 100069, P.R. China

E-mail: zhangyulin1968@126.com

Professor Hongliang Guo, Department of General Surgery, Shandong Cancer Hospital Affiliated to Shandong University, Shandong Academy of Medical Sciences, 440 Jiyan Road, Jinan, Shandong 250117, P.R. China

E-mail: hliangbb@163.com

${ }^{*}$ Contributed equally

Key words: colorectal cancer, gastrointestinal cancer, gastric cancer, mitochondria D-loop region, pathogenesis
The mutations of the mtDNA D-loop were primarily homoplasmic in GIC and often transitioned at pyrimidine sites. Mitochondrial microsatellite instability, including the formation of poly-cytidine stretches, was common in GIC. These results demonstrate the occurrence of mtDNA D-loop mutations in GIC in Chinese patients and support the correlation of these mutations with carcinoma progression. Over-activated DNA repair function possibly repairs the GIC mtDNA lesions.

\section{Introduction}

Gastric cancer (GC) and colorectal cancer (CRC) are worldwide public health problems; GC is the fourth most common type of carcinoma and the second most common cause of carcinoma-associated mortality, and CRC is the second most common cause of carcinoma-associated mortality with an annual incidence of 1,000,000 cases and an annual mortality of $>500,000$ cases (1). In China, the incidence of GC ranks third among all malignant tumors and the mortality rate was 26.3/100,000 in 2005 (2); the incidence of CRC ranked fourth of all cancer types and the estimated mortality rate was ranked the fifth leading cause of cancer-associated mortality in all cancer types in 2011 (3). However, the pathogenesis of these diseases remains to be fully elucidated. Previous studies have focused on the induced oncogenes and inhibited tumor suppressor genes, as well as the dysfunction of mismatch base repair in nuclear DNA, which does not fully explain the pathogenesis and development of these diseases. Mitochondria can generate adenosine triphosphate via oxidative phosphorylation and in turn control essential cellular activities. The displacement loop region (D-loop) is the main noncoding area of mitochondrial DNA (mtDNA). mtDNA mutations in the D-loop region and somatic mtDNA mutations have been described to be common in various types of primary human cancer types including hepatocellular carcinoma, and bladder, breast and lung cancers $(4,5)$; however, their role in the pathogenesis of gastrointestinal cancer (GIC) is controversial. In the present study, whether somatic mtDNA and D-loop mutations 
occurred in Chinese patients with GIC and their association with disease progression were investigated.

\section{Materials and methods}

Patients and tissues. Tumor and para-tumor tissues were obtained from GC and CRC patients who underwent surgical tumor resection at the Fourth General Surgery Division, Shandong Cancer Hospital (Jinan, China) between February 2012 and August 2012. Tumor tissues were pathologically diagnosed as GC or CRC, and para-tumor tissues were confirmed to be non-cancerous by experienced pathologists. The inclusion criteria included: i) Preoperative pathological biopsy and postoperative histopathology confirmed the diagnosis of GIC; ii) patients without other diagnosed tumors or diseases; and iii) patients or their families all provided signed informed consent. The exclusion criteria included: ii) Patients with incomplete clinical data available; ii) patients diagnosed with other types of tumors and diseases; and iii) patients and their families who refused to provide informed consent. Patient demographics and clinical characteristics are listed in Table I. Among the participants, there were 18 patients with GC, 21 patients with colon cancers (CC) and 30 patients with rectal cancer (RC); their average ages were 55.1, 54 and 57.4 years, respectively. Men appeared to be over-represented, accounting for 13/18 GC patients, 13/21 CC patients and 20/30 $\mathrm{RC}$ patients. The majority of these patients were diagnosed with tumor node metastasis (TNM) stages II-III and grades I-III. The present study was approved by the Ethics Committees of Shandong Cancer Hospital. Written informed consent was obtained from all study participants.

Immunohistochemistry staining. GI tissues were fixed with $10 \%$ formalin at $4^{\circ} \mathrm{C}$ for $24 \mathrm{~h}$ and then paraffin-embedded; sections $4-\mu$ m-thick were cut and immunohistochemical staining was performed. Tissue sections were first deparaffinized and rehydrated, followed by heat-induced epitope retrieval at $95-100^{\circ} \mathrm{C}$, washing with $100 \%$ Ethanol 2 for $5 \mathrm{~min}, 90 \%$ Ethanol 1 for $5 \mathrm{~min}, 70 \%$ Ethanol 1 for $5 \mathrm{~min}$ and $\mathrm{ddH}_{2} \mathrm{O} 1$ for $5 \mathrm{~min}$, and then treated with a $10 \mathrm{mmol} / \mathrm{l}$ citrate buffer ( $\mathrm{pH}$ 6.0). Next, $3 \% \mathrm{H}_{2} \mathrm{O}_{2}$ was used to block endogenous peroxidase and sections were blocked with PBS containing 10\% fetal bovine serum (Gibco; Thermo Fisher Scientific, Inc., Waltham, MA, USA) at room temperature for $1 \mathrm{~h}$. Then, sections were incubated with anti-8-hydroxyguanine (oxo-G; cat. no. 4354-MC-050; Trevigen, Inc., Gaithersburg, MD, USA) and anti-8-oxo-20-deoxyguanosine glycosylase 1 (OGG1; cat. no. NBP2-52724; Novus Biologicals, LLC, Littleton, CO, USA) antibodies, diluted with blocking reagent $(1: 1,000)$, overnight at $4^{\circ} \mathrm{C}$, followed by incubation with a biotin-free horseradish peroxidase-conjugated secondary antibody (cat. no. pv9005; Beijing Zhongshan Golden Bridge Biotechnology Co., Ltd., Beijing, China); diluted with blocking reagent $(1: 1,000)$ for $1 \mathrm{~h}$ at room temperature. Visualization was performed with 3,3'-diaminobenzidine. The slides were viewed and photographed under a fluorescent inverted microscope (Olympus IX71; Olympus Corporation, Tokyo, Japan), and positively stained cells were counted using Image Pro Plus 6.0 software (Media Cybernetics, Inc., Rockville, MD, USA).
DNA isolation, and cloning and sequencing of the mtDNA D-loop. Total DNA from the tumor and para-tumor tissues was isolated using a DNA extraction kit (Qiagen China Co., Ltd., Shanghai, China) following the manufacturer's protocol, and polymerase chain reaction (PCR) was performed to amplify the mtDNA D-loop region using high-fidelity Platinum Taq polymerase (Invitrogen; Thermo Fisher Scientific, Inc.). The primer pairs and PCR procedure for the D-loop in the present study have been described in our previous study (6). The pGEM-18T vector (Takara Biotechnology Co., Ltd., Dalian, China) was used to clone the PCR products, and 10-12 randomly selected clones/samples were sequenced on an ABI 3730 genetic analyzer (Thermo Fisher Scientific, Inc.). The D-loop nucleotide sequences from each clone were analyzed and manually adjusted using NCBI BLAST(blast.ncbi.nlm.nih.gov/Blast.cgi) and free BioEdit software (version 7.1.3; Ibis Therapeutics, Carlsbad, CA, USA). All sequences have been submitted to GenBank (accession nos. KY402468-KY403500).

Reverse transcription-quantitative PCR (RT-qPCR). The RT-qPCR assay for mtDNA deletion quantification was performed using the SYBR Green (Beijing Biomed Biotechnology Co., Ltd., Beijing, China)method based on the relative nicotinamide adenine dinucleotide hydride dehydrogenase subunit 1 (ND1)/ND4-quantification method as well as $2^{-\Delta \Delta \mathrm{Cq}}$ as previously reported $(6,8-11)$, and was performed using the TaqMan 7900HT system (Thermo Fisher Scientific, Inc.). The primers used in the present study were as follows: Reference gene, Homo sapiens mitochondrion complete genome (Gen-Bank NC 012920); ND1 forward, 5'-CCCTAA AACCCGCCACATCT-3' and reverse, 5'-TGGAATCGAGAG TGGTAGCGAG-3'; ND4 forward, 5'-CCATTCTCCTCCTAT CCCTCAAC-3' and reverse, 5'-TTTATATCAAATTGGTTT TGTAGTCTAACAC-3' (synthesized by Invitrogen; Thermo Fisher Scientific, Inc.). The procedures were similar to those described in our previous report $(7,12)$. Briefly, $250 \mathrm{nM}$ probe and $300 \mathrm{nM}$ primer were used in the PCR reaction mix. The qPCR thermocycling conditions were as follows: $5 \mathrm{~min}$ at $95^{\circ} \mathrm{C}$, followed by 50 cycles of $15 \mathrm{sec}$ at $95^{\circ} \mathrm{C}$ and $1 \mathrm{~min}$ at $60^{\circ} \mathrm{C}$. qPCR reactions were performed in triplicate for each sample. Double-distilled water was used as a control reaction and was subjected to the same conditions as the test reactions.

Sequence analysis. The sequences were analyzed as previously described (13-15). Briefly, the obtained nucleotide sequences from each clone were assembled and error checked using the Vector NTI suite 7.0 ContigExpress software package (Thermo Fisher Scientific, Inc.). The sequences were then aligned to the reference sequence (Gen-Bank NC 012920) using the Clustal W multiple sequence alignment program (www.ebi.ac.uk/Tools/ msa/clustalw2/), then the nucleotide mutations were identified and calculations were performed. Shannon entropy (www.hiv .lanl.gov/content/sequence/ENTROPY/entropytwo.html), as a measure of variation in mtDNA D-loop sequence alignments, was used to determine whether there were more highly variable areas in tumors when compared with the para-tumors. The sequences were then aligned to the reference sequence using the MITOMASTER web tool in the Mitomap database (www.mitomap.org/) to check for mtDNA mutations. Microsatellite instability (MSI), a simple repetitive sequence 
Table I. Demographics and clinical characteristics of the patients recruited to the present study.

\begin{tabular}{|c|c|c|c|}
\hline \multirow[b]{2}{*}{ Characteristics } & \multicolumn{3}{|c|}{ Carcinoma type } \\
\hline & $\begin{array}{l}\text { Gastric } \\
\text { cancer } \\
(\mathrm{n}=18)\end{array}$ & $\begin{array}{l}\text { Colon } \\
\text { cancer } \\
(n=21)\end{array}$ & $\begin{array}{c}\text { Rectum } \\
\text { cancer } \\
(n=30)\end{array}$ \\
\hline Sex (male) & 13 & 13 & 20 \\
\hline \multicolumn{4}{|l|}{ Age (years) } \\
\hline Mean & 55.1 & 54.0 & 57.4 \\
\hline Range & $40-68$ & $30-71$ & $34-75$ \\
\hline \multicolumn{4}{|l|}{ TNM stage (n) } \\
\hline I & 0 & 0 & 4 \\
\hline II & 2 & 10 & 9 \\
\hline III & 14 & 5 & 14 \\
\hline IV & 2 & 6 & 3 \\
\hline \multicolumn{4}{|l|}{ Grade (n) } \\
\hline $\mathrm{I}$ & 2 & 7 & 5 \\
\hline II & 6 & 12 & 20 \\
\hline III & 10 & 1 & 5 \\
\hline IV & 0 & 1 & 0 \\
\hline \multicolumn{4}{|l|}{ Type of surgery (n) } \\
\hline Local resection & 10 & 17 & 16 \\
\hline Organ resection & 8 & 4 & 14 \\
\hline Multiorgan resection & 0 & 0 & 0 \\
\hline $\operatorname{CEA}(\mathrm{n} \geq 5 \mu \mathrm{g} / \mathrm{l})$ & 5 & 11 & 10 \\
\hline CA19-9 (n $\geq 37 \mathrm{U} / \mathrm{ml})$ & 6 & 10 & 3 \\
\hline CA72-4 (n $\geq 6 \mathrm{U} / \mathrm{ml})$ & 6 & N/A & N/A \\
\hline \multicolumn{4}{|l|}{ Risk factors } \\
\hline \multicolumn{4}{|l|}{ Tobacco use (n) } \\
\hline Current & 7 & 7 & 3 \\
\hline Former & 3 & 2 & 3 \\
\hline Never & 8 & 12 & 24 \\
\hline \multicolumn{4}{|l|}{ Alcohol use (n) } \\
\hline Current & 8 & 4 & 3 \\
\hline Former & 1 & 3 & 1 \\
\hline Never & 9 & 14 & 26 \\
\hline Family history (n) & 1 & 3 & 1 \\
\hline Polyps (n) & 1 & 3 & 1 \\
\hline Inflammatory disease $(n)^{a}$ & 3 & 2 & 0 \\
\hline Unhealthy diet $(\mathrm{n})^{\mathrm{b}}$ & 1 & 0 & 0 \\
\hline
\end{tabular}

anflammatory diseases including Crohn's disease, ulcerative colitis or long-term stomach inflammation. ${ }^{\mathrm{b}} \mathrm{As}$ determined by the dietary guidelines for Chinese residents (2016) (6). N/A, not applicable.

change caused by a mismatch repair gene mutation, was also examined in 69 Chinese patients via alignment of sequences to the reference sequence.

Statistical analysis. The results are presented as the mean \pm standard error of the mean. Statistical significance was determined by one-way analysis of variance with post hoc correction using the Tukey's multiple comparison test. Nonparametric Mann-Whitney, Chi-square, or Fisher's exact tests were used to compare nonparametric data. All statistical analyses were performed using SPSS software (version 16.0; SPSS Inc., Chicago, IL, USA), and $\mathrm{P}<0.05$ was considered to indicate a statistically significant difference.

\section{Results}

No increased mtDNA loss was observed in GIC. In the present study, whether mtDNA deletions occurred in GIC were assessed via qPCR. The ND1 gene is located in the minor arc of mtDNA and is rarely deleted; however, the ND4 gene is located at the major arc of mtDNA and is frequently deleted. ND1/ND4 relative qPCR was used to detect mtDNA deletions via the $2^{-\Delta \Delta \mathrm{Cq}}$ method in the present study. The results demonstrated that the relative amount of mtDNA copies were 99.44\% in GC tumors and $99.58 \%$ in GC para-tumors, $99.44 \%$ in CC tumors and $99.35 \%$ in CC para-tumors, and $99.32 \%$ in RC tumors and $99.13 \%$ in RC para-tumors (Fig. 1). No significant mtDNA deletions were noted in the GC, CC or RC tumor tissues when compared with para-tumor tissues. Furthermore, the relative amount of mtDNA copies between the different clinical carcinoma stages were compared; however, no mtDNA deletions in stage III-IV GC, CC or RC were identified (data not shown).

DNA oxidative damage and over-activated DNA repair in GIC. Oxidative damage has been reported in the mtDNA of tumor cells (16). DNA oxidative damage commonly produces oxo-G, and OGG1initiates base excision repair, which removes oxo-G damaged DNA (17). In the present study, the expression of oxo-G and OGG1 was determined in GIC tumor and para-tumor tissues using immunohistochemistry staining, as described in our previous studies $(7,18)$. No significant increases were observed in oxo-G $(92 \pm 1$ vs. $90 \pm 2 \%)$ or OGG1 $(94 \pm 1$ vs. $92 \pm 2 \%$ ) expression in GC tissues when compared with para-GC tissues (Fig. 2A and B). In addition, no significant difference in oxo-G expression was observed between $\mathrm{CC}$ tissues $(94 \pm 1 \%)$ and para-CC tissues $(84 \pm 4 \%)$, but OGG1 expression was higher in CC tissues $(97 \pm 1 \%)$ when compared with para-CC tissues ( $83 \pm 1 \%$; Fig. $2 \mathrm{C}$ and D). However,

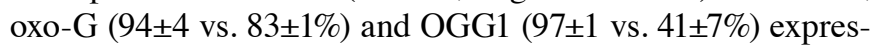
sion levels were increased in RC tissues when compared with para-RC tissues (Fig. 2E and F). These results indicated that oxidative damage and over-activated DNA repair functioning occurred in GIC.

Somatic mtDNA D-loop mutations in GIC. To identify somatic mutations in the D-loop of mtDNA in GIC, Shannon entropy was used to identify highly variant regions in the D-loop of mtDNA. The results revealed that GC had two highly variant regions located at nucleotide position (np) 75-173 and np 314-447; CC had a highly variant region located at np 307-476, which was similar to the second highly variant region of $\mathrm{GC}$; and $\mathrm{RC}$ had two highly variant regions located at np 16069-16177 and np 517-576, which were significantly different from the locations in GC and CC (Fig. 3A). Then, the sequences in the mtDNA D-loop region from tumor and 


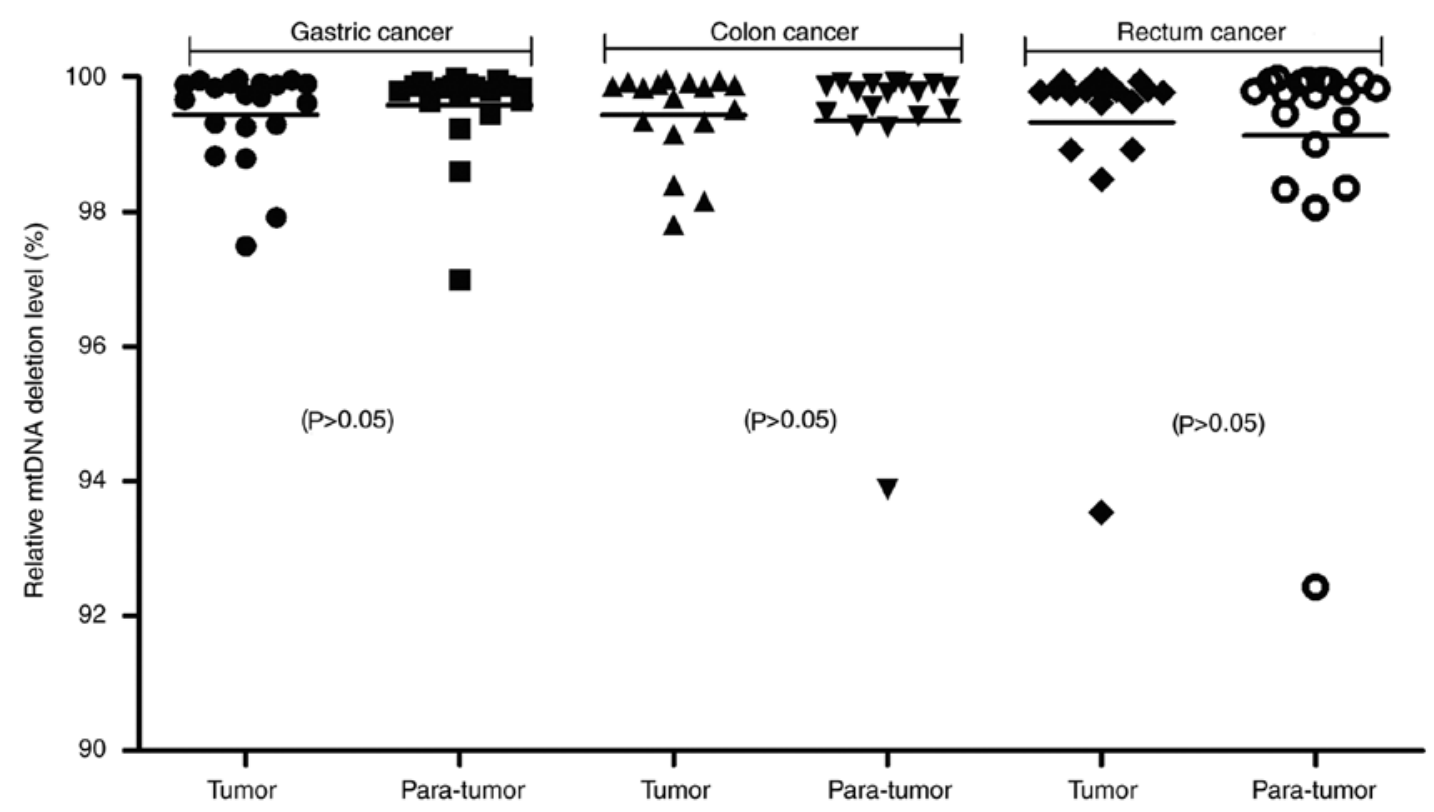

Figure 1. No increases in mtDNA loss were observed in gastrointestinal cancer. The calculated percentage of mtDNA copies are presented for tumor and para-tissues from patients with gastric, colon and rectum cancer. mtDNA, mitochondrial DNA.

para-tumor tissues from $18 \mathrm{GC}, 21 \mathrm{CC}$ and $30 \mathrm{RC}$ patients were directly analyzed. The results demonstrated a total of 221 mutations in 196 sequences from the tumor tissues of the 18 patients with GC; this number was significantly higher than that observed in the paired para-tumor tissues, which contained 141 mutations in 179 sequences $(\mathrm{P}<0.05)$. Similarly, a high frequency of mutation(s) was identified in the 21 patients with CC (153 mutations in 155 sequences from the tumor tissues vs. 107 mutations in 154 sequences from the para-tumor tissues) and the 30 patients with RC (166 mutations in 183 sequences from the tumor tissues vs. 104 mutations in 168 sequences from the para-tumor tissues; both $\mathrm{P}<0.05$; Table II). These results indicated that all three types of GIC contained more somatic mutations than the normal para-tumor tissues. Based on the delineation of the functional regions of the mtDNA D-loop in previous reports $(19,20)$, the mutation sites were analyzed, and it was revealed that these mutations clustered in the replication origin of the $\mathrm{H}$-strand $(\mathrm{P}<0.05)$ and conserved sequence block 2. Furthermore, GC and RC also possessed somatic mutation(s) in an unknown functional region $(\mathrm{P}<0.05$; Fig. 3B; Table II).

More severe mtDNA D-loop mutations are observed in advanced stages of GIC. It is well known that tumor staging is an important prognostic factor for malignant neoplasms (21). In the present study, the mutation rate of the mtDNA D-loop region between tumors of different stages and para-tumor tissues were compared. The results demonstrated that the mean mutation rate of the mtDNA D-loop region was significantly higher in stage III-IV GC tissues when compared with in para-tumor tissues $(1.46 \pm 1.02$ vs. $0.75 \pm 0.38$; $\mathrm{P}<0.05)$; however, the increase in the D-loop mutation rate was not significant in stage I-II GC $(1.04 \pm 0.22$ vs. $0.84 \pm 0.05$; P>0.05; Fig. $4 \mathrm{~A})$. Similar analysis revealed that early and advanced stages of $\mathrm{CC}$ and RC had a significantly higher D-loop mutation rate when compared with para-tumors: $1.01 \pm 0.43$ vs. $0.55 \pm 0.16$ in stage I-II CC; $1.62 \pm 1.39$ vs. $0.66 \pm 0.41$ in stage III-IV CC; $0.94 \pm 0.39$ vs. $0.72 \pm 0.32$ stage I-II RC; and $1.39 \pm 1.56$ vs. $0.73 \pm 0.37$ stage III-IV RC (all $\mathrm{P}<0.05)$. The mutation rates of stage III-IV tumors were greater when compared with those of stage I-II tumors (Fig. 4B and C). These results indicated that the later the GC stage, the more severe the mtDNA D-loop mutations.

Homoplasmic mutations of the mtDNA D-loop in GIC. Certain studies have indicated that mtDNA mutations in the coding regions of CRC are primarily transitions; A-T and G-C are common in the D-loop region (22). In the present study, the mutation types in the mtDNA D-loop in GIC were also analyzed. The results revealed that of the single-base mutations, transitions accounted for $83.86 \%$ in $\mathrm{GC}, 96.74 \%$ in $\mathrm{CC}$ and $93.9 \%$ in RC. The T-C base substitution was the most common (44.11\% in GC, $52.29 \%$ in $\mathrm{CC}$ and $45.12 \%$ in $\mathrm{RC}$ ), followed by C-T (20.10\% in GC, $22.88 \%$ in CC and $18.29 \%$ in $\mathrm{RC})$; and the $\mathrm{G}-\mathrm{A}$ transition was relatively rare $(2.94 \%$ in GC, $5.23 \%$ in CC and $2.44 \%$ in RC; Table III). These results suggested that the mutations of the mtDNA D-loop were primarily homoplasmic in GIC and were often transitions at pyrimidine sites.

Mitochondrial MSI (mtMSI) in GIC. mtMSI has been reported to frequently occur in GC and CRC $(23,24)$. In the present study, the mtMSI in 69 Chinese patients with GIC were analyzed. It was revealed that polynucleotide stretches were common and resulted from a 1-3 cytosine insertion or cytosine deletion. Among them, the percentage of sequences containing a continuous 10 -cytosine stretch was $11.7 \%$ in GC, $13.8 \%$ in CC 11.7 and $20.9 \%$ in RC. The percentage of sequences containing a continuous 7-cytosine stretch was $40.3 \%$ in GC, $68.6 \%$ in CC 11.7 and $47 \%$ in RC (Table IV). Furthermore, repeated $\mathrm{AC}$ stretches were observed in $\mathrm{GC}$, which were caused by a 1-2 CA insertion or CA deletion, and the total 
A

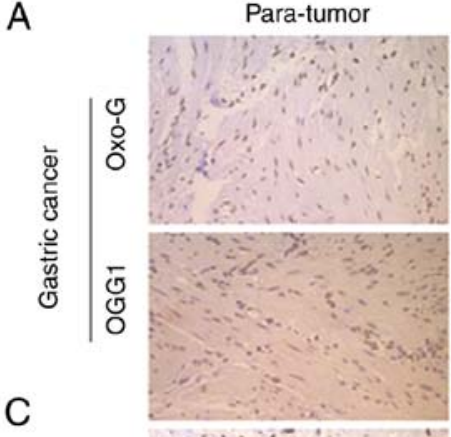

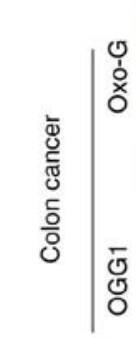

E

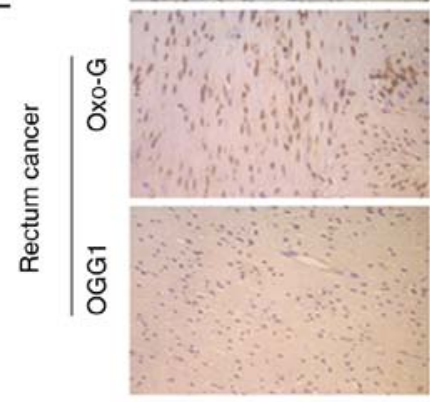

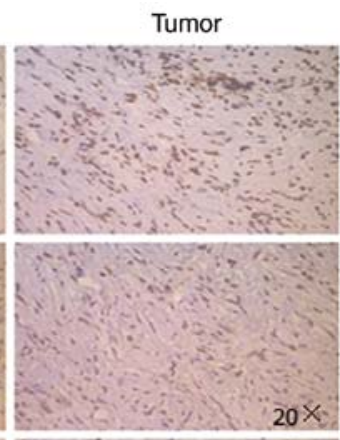
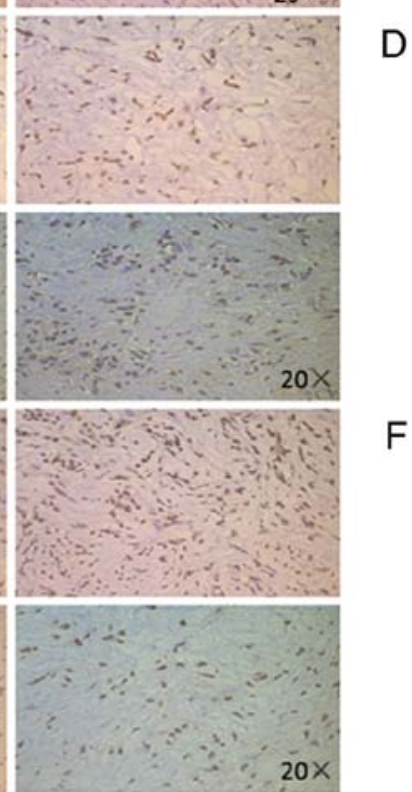

B

$\mathrm{F}$

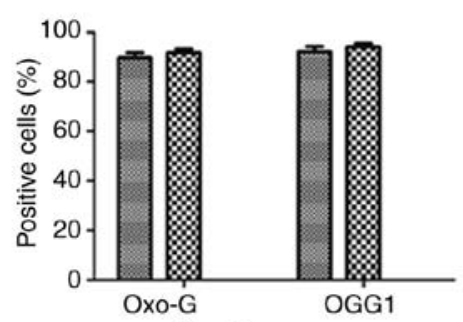

Gastric cancer

D
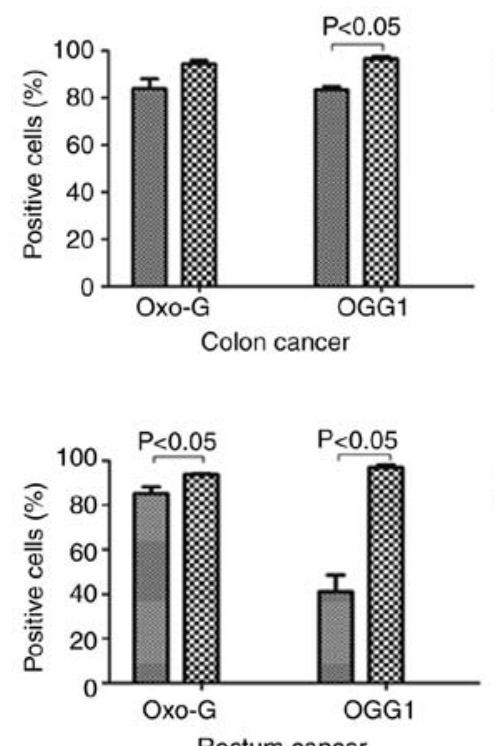

Para-tumo $\$$ Tumor

Figure 2. DNA oxidative damage and over-activated DNA repair in gastrointestinal cancer: (A and B) Gastric cancer, (C and D) colon cancer and (E and F) rectum cancer. (A, C and E) Representative immunohistochemical staining demonstrating the morphology of tissues (magnification, $\mathrm{x} 20$ ). (B, D and F) Graphs comparing the number of immunohistochemically-positive cells between the tumor and para-tumor groups. $\mathrm{P}<0.05$, as indicated. oxo-G, 8 -hydroxyguanine; OGG1, 8-oxo-20-deoxyguanosine glycosylase 1.
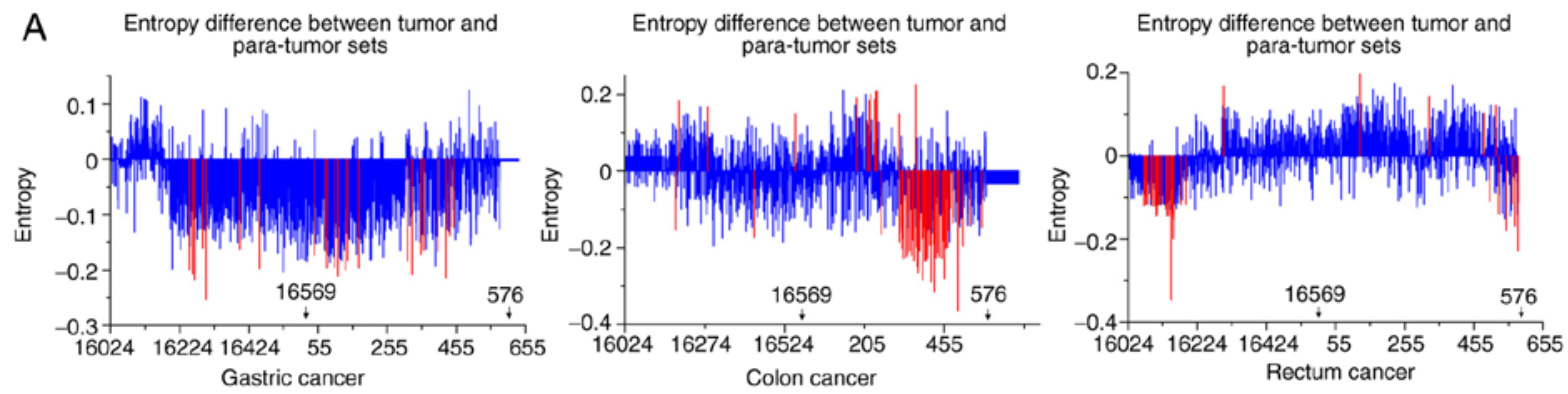

B

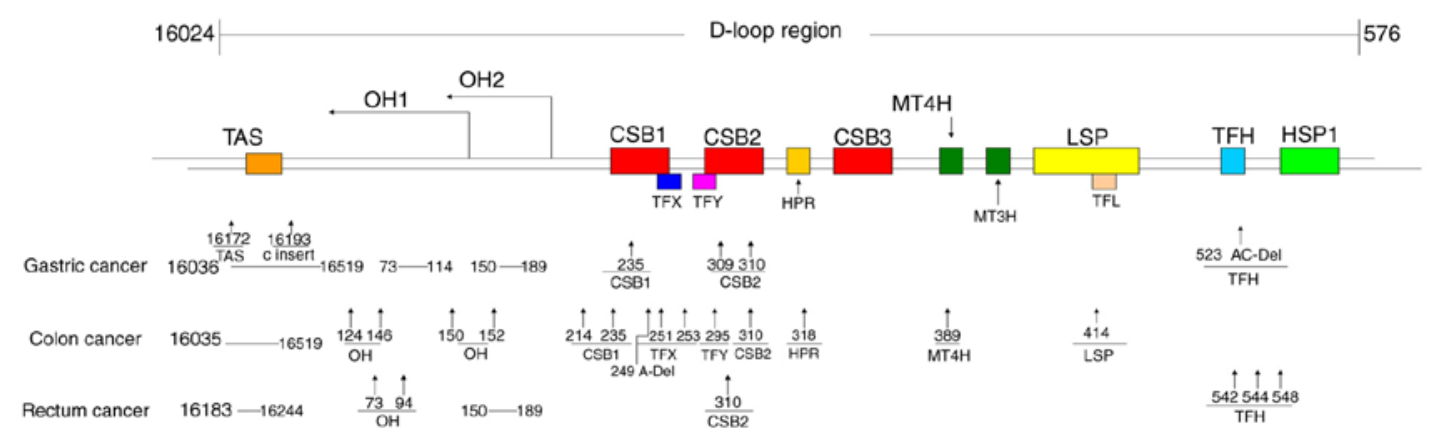

Figure 3. Somatic mitochondrial DNA D-loop mutations in gastrointestinal cancer. (A) Difference in Shannon entropy between tumor and para-tumor tissues in gastrointestinal cancer. Residue-specific entropy was computed and significant sites $(\mathrm{P}<0.05)$ are presented in red on the plots. $(\mathrm{B}) \mathrm{A}$ diagrammatic sketch presenting the mtDNA D-loop mutations clustered in the replication OH1, the CSB2 and the unknown functional regions. OH1, origin of the H-strand; CSB2, conserved sequence block 2 . 
Table II. Distribution of mtDNA D-loop mutations in gastrointestinal cancer.

\begin{tabular}{|c|c|c|c|c|c|c|c|c|c|}
\hline \multirow[b]{2}{*}{ Mitomap } & \multicolumn{3}{|c|}{ Gastric cancer } & \multicolumn{3}{|c|}{ Colon cancer } & \multicolumn{3}{|c|}{ Rectum cancer } \\
\hline & $\begin{array}{c}\text { Tumor } \\
\left(\mathrm{n}^{\mathrm{a}}=196\right)\end{array}$ & $\begin{array}{l}\text { Para-tumor } \\
\quad(\mathrm{n}=179)\end{array}$ & P-value & $\begin{array}{c}\text { Tumor } \\
(\mathrm{n}=153)\end{array}$ & $\begin{array}{l}\text { Para-tumor } \\
(\mathrm{n}=154)\end{array}$ & P-value & $\begin{array}{c}\text { Tumor } \\
(\mathrm{n}=183)\end{array}$ & $\begin{array}{l}\text { Para-tumor } \\
\quad(n=168)\end{array}$ & P-value \\
\hline $\mathrm{OH} 1$ & 135 & 87 & $<0.05$ & 68 & 40 & $<0.05$ & 85 & 48 & $<0.05$ \\
\hline $\mathrm{OH} 2$ & - & - & - & 16 & 12 & $>0.05$ & 18 & 12 & $>0.05$ \\
\hline CSB1 & 1 & 1 & - & 6 & 4 & - & - & - & - \\
\hline TFX & - & - & - & 3 & 0 & - & - & - & - \\
\hline TFY & - & - & - & 1 & 0 & - & - & - & - \\
\hline CSB2 & 17 & 8 & $>0.05$ & 17 & 16 & $>0.05$ & 16 & 11 & $>0.05$ \\
\hline HPR & - & - & - & 1 & 1 & - & - & - & - \\
\hline CSB3 & - & - & - & - & - & - & - & - & - \\
\hline MT4H & - & - & - & - & - & - & - & - & - \\
\hline МT3H & 1 & 0 & - & 15 & 11 & $>0.05$ & - & - & - \\
\hline LSP & - & - & - & 1 & 0 & - & - & - & - \\
\hline TFL & - & - & - & - & - & - & - & - & - \\
\hline TFH & 9 & 7 & - & - & - & - & 3 & 0 & - \\
\hline HSP1 & - & - & - & - & - & - & - & - & - \\
\hline TAS & 7 & 6 & - & 1 & 1 & - & - & - & - \\
\hline UNKNOW & 51 & 32 & $<0.05$ & 25 & 22 & $>0.05$ & 44 & 33 & $<0.05$ \\
\hline Sum & 221 & 141 & $<0.05$ & 154 & 107 & $<0.05$ & 166 & 104 & $<0.05$ \\
\hline
\end{tabular}

The data were statistically analyzed using a nonparametric paired Chi-square test. $\mathrm{n}^{\mathrm{a}}$ refers to the sequence number. The value in the table equals the base mutation number. OH, replication origin of H-strand; CSB, conserved sequence block; LSP, L-strand promoter; mt-/mtDNA, mitochondrial DNA; TF, mtTF1 binding site; TFY, mtTF1 binding site; HPR, Replication primer; MT4H, mt4 H-strand control element; MT3H, mt3 H-strand control element; TFL, mtTF1 binding site; TFH, mtTF1 binding site; HSP1, Major H-strand promoter; TAS, Termination-associated sequence; UNKNOW, unknown functional area.
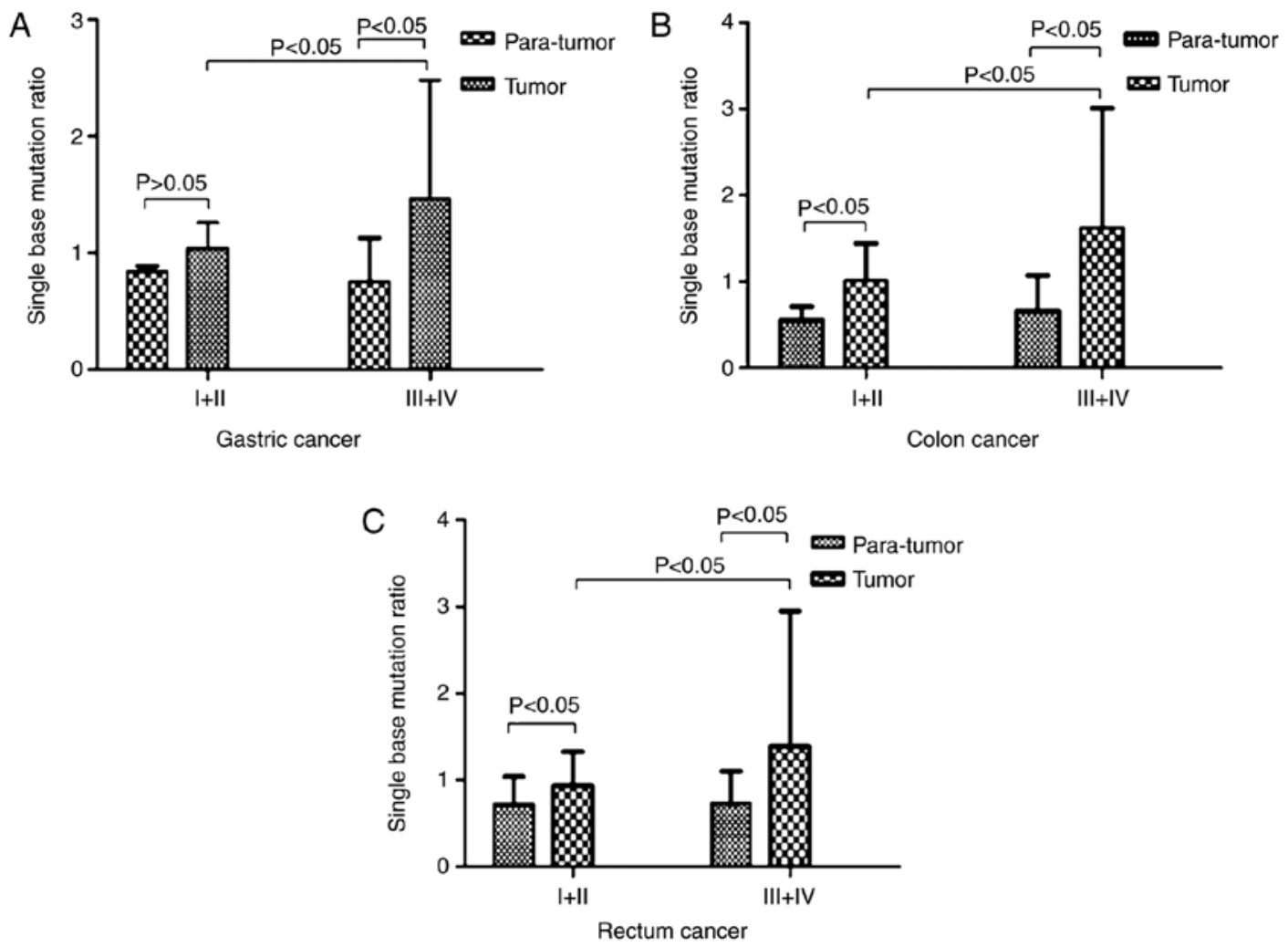

Figure 4. More severe mitochondrial DNA D-loop mutations are present in the advanced stages of gastrointestinal cancer: (A) Gastric, (B) colon and (C) rectum cancer. Stages I-II were defined as early cancer stages and stages III-IV as advanced cancer stages. P $<0.05$, as indicated. 
Table III. Subtypes of single base mutation in gastrointestinal cancer.

\begin{tabular}{|c|c|c|c|c|c|c|c|c|c|}
\hline \multirow[b]{2}{*}{ Mutation subtype } & \multicolumn{3}{|c|}{ Gastric cancer } & \multicolumn{3}{|c|}{ Colon cancer } & \multicolumn{3}{|c|}{ Rectum cancer } \\
\hline & Sites & Tumor & PCT $(\%)$ & Sites & Tumor & РCT (\%) & Sites & Tumor & РCT (\%) \\
\hline \multicolumn{10}{|l|}{ Transition } \\
\hline A-G & 12 & 34 & 16.67 & 6 & 25 & 16.34 & 6 & 46 & 28.05 \\
\hline G-A & 4 & 6 & 2.94 & 6 & 8 & 5.23 & 3 & 4 & 2.44 \\
\hline $\mathrm{C}-\mathrm{T}$ & 14 & 41 & 20.10 & 10 & 35 & 22.88 & 8 & 30 & 18.29 \\
\hline $\mathrm{T}-\mathrm{C}$ & 18 & 90 & 44.11 & 18 & 80 & 52.29 & 13 & 74 & 45.12 \\
\hline Sum & & & 83.86 & & & 96.74 & & & 93.9 \\
\hline \multicolumn{10}{|l|}{ Transversion } \\
\hline $\mathrm{A}-\mathrm{C}$ & 2 & 11 & 5.39 & 1 & 4 & 2.61 & 1 & 8 & 4.88 \\
\hline A-T & 1 & 1 & 0.49 & 0 & 0 & 0 & 0 & 0 & N/A \\
\hline C-A & 0 & 0 & 0 & 1 & 1 & 0.65 & 1 & 1 & 0.61 \\
\hline $\mathrm{C}-\mathrm{G}$ & 0 & 0 & 0 & 0 & 0 & 0 & 1 & 1 & 0.61 \\
\hline $\mathrm{G}-\mathrm{C}$ & 1 & 1 & 0.49 & 0 & 0 & 0 & 0 & 0 & N/A \\
\hline $\mathrm{T}-\mathrm{G}$ & 1 & 20 & 9.80 & 0 & 0 & 0 & 0 & 0 & N/A \\
\hline Sum & & & 16.14 & & & 3.26 & & & 6.1 \\
\hline
\end{tabular}

Where 'Sites' denotes the number of mutation sites; 'Tumor' denotes the absolute counts of base mutations in a tumor; and 'PCT (\%)' denotes the percentage of base mutations in tumors. N/A, not applicable; PCT, percentage.

Table IV. Mitochondrial microsatellite instability in gastrointestinal cancer.

\begin{tabular}{|c|c|c|c|c|c|c|c|c|c|}
\hline \multirow[b]{2}{*}{ Type } & \multicolumn{3}{|c|}{$\begin{array}{l}\text { СССССТCCCC } \\
\left(16184-16193^{\mathrm{a}},\right. \\
\left.\mathrm{T} \rightarrow \mathrm{C},(\mathrm{C}) 10^{\mathrm{b}}\right)(\%)\end{array}$} & \multirow[b]{2}{*}{ Type } & \multicolumn{3}{|c|}{$\begin{array}{c}\text { CCCCCCC } \\
(303-309,(\mathrm{C}) 7)(\%)\end{array}$} & \multirow{2}{*}{$\begin{array}{l}\text { C } \\
\text { C } \\
(\end{array}$} & \multirow{2}{*}{$\begin{array}{r}\text { CACACACA } \\
\text { CA (515-524 } \\
\begin{array}{r}\text { (CA) 5) }(\%) \\
\begin{array}{r}\text { Gastric } \\
\text { cancer }\end{array}\end{array}\end{array}$} \\
\hline & $\begin{array}{l}\text { Gastric } \\
\text { cancer }\end{array}$ & $\begin{array}{l}\text { Colon } \\
\text { cancer }\end{array}$ & $\begin{array}{l}\text { Rectum } \\
\text { cancer }\end{array}$ & & $\begin{array}{l}\text { Gastric } \\
\text { cancer }\end{array}$ & $\begin{array}{l}\text { Colon } \\
\text { cancer }\end{array}$ & $\begin{array}{l}\text { Rectum } \\
\text { cancer }\end{array}$ & & \\
\hline $\mathrm{C} 1$ insert & 7.1 & 7.2 & 7.7 & $\mathrm{C} 1$ insert & 34.7 & 45.1 & 35.0 & CA1 insert & 4.1 \\
\hline $\mathrm{C} 2$ insert & 3.6 & 3.9 & 4.4 & $\mathrm{C} 2$ insert & 5.6 & 15.0 & 10.9 & CA2 insert & 1.5 \\
\hline C3 insert & 1.0 & 2.0 & 2.2 & C3 insert & 0 & 5.9 & 1.1 & CA1 deletion & 31.6 \\
\hline $\mathrm{C} 1$ deletion & 0 & 0.7 & 6.6 & C3 deletion & 0 & 2.6 & 0 & - & - \\
\hline Sum & 11.7 & 13.8 & 20.9 & Sum & 40.3 & 68.6 & 47 & Sum & 37.2 \\
\hline
\end{tabular}

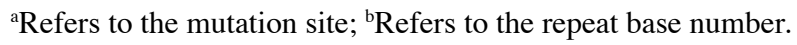

percentage of this sequence was $37.2 \%$ (Table IV). The formation of the polynucleotide stretch is presented in Fig. 5. These results suggested that mtMSI occurs in Chinese patients with GIC.

\section{Discussion}

It is thought that the inactivation of mitochondrial energy metabolism does not occur in cancer cells with mutations in mitochondrial genes; however, the mitochondrial bioenergetic and biosynthetic state may be altered through a series of modulations of signal transduction pathways between the nucleus and mitochondria $(25,26)$. Although certain studies do not support the idea of D-loop alterations of the mtDNA genome and their carcinogenic role in CRC $(27,28)$, increased mtDNA mutations, deletions and even mitochondrial dysfunction have been identified in GIC (29-33), and even in certain precancerous lesions, including ulcerative colitis lesions and adenomatous polyps (34). Mitochondrial dysfunction is associated with tumor development and progression (35). Various mtDNA mutations have been observed to modify tumor progression depending on the level of respiratory complex I (36), and defective mitochondrial respiration may be restored and tumor-forming ability regained via mitochondrial acquisition (37). In GC, the mtDNA repair system does not appear to be disrupted (38). The present study supports the 
WANG et al: MtDNA D-LOOP LESIONS IN GIC

3701

A

C A A A A C C C C C T C C C C A T G C

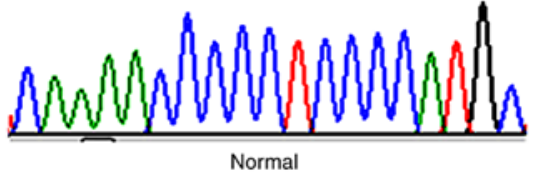

C A A A A C C C C C C C A T G C

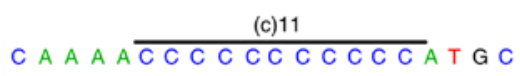

mowhoritionich

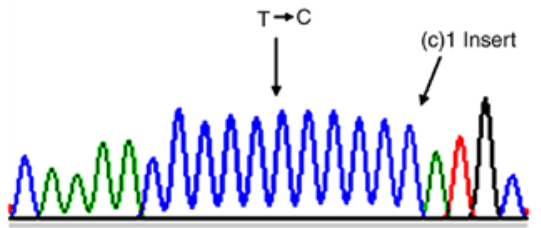

(c) 1 Deletion

(c) 1 Insertion

C A A A AC CCCCCCCCCCCAT GC

C A A A A $\frac{(\text { c) } 13}{\operatorname{ccccccccc} A T G C}$

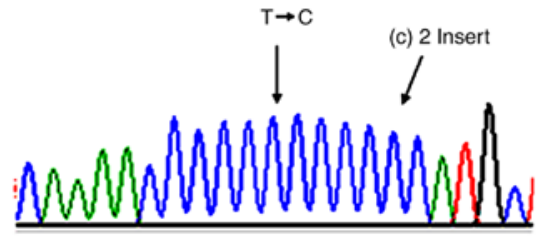

$\begin{array}{ll}T \rightarrow C & \text { (c) } 3 \text { Insert }\end{array}$

(c)2 Insertion

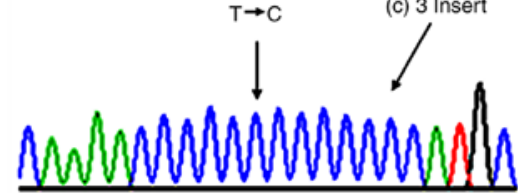

(c)3 Insertion

B

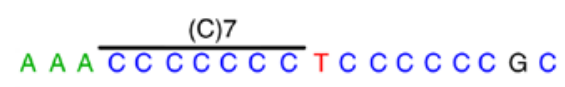

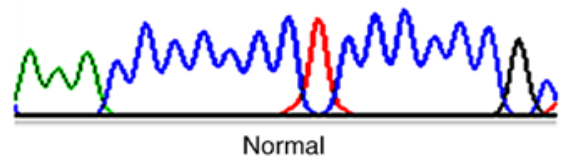

A A A C C C C T C C C C C C G C T

AAA CCCCCCCC T C C CCCCGCT
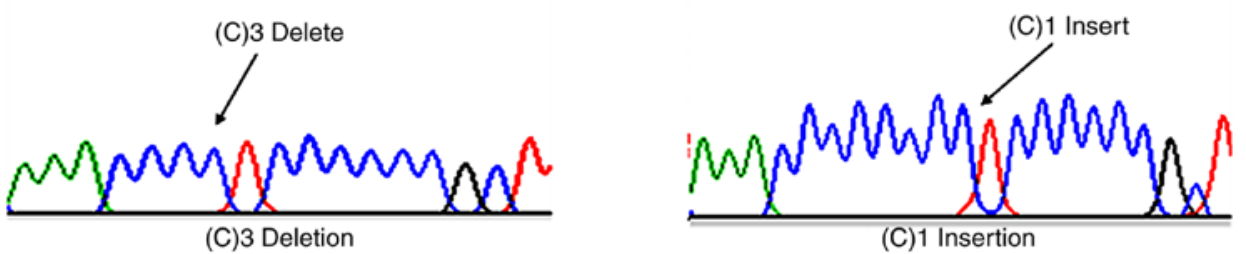

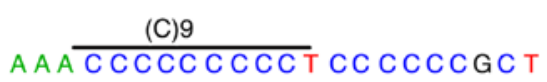

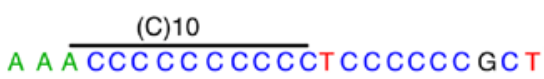
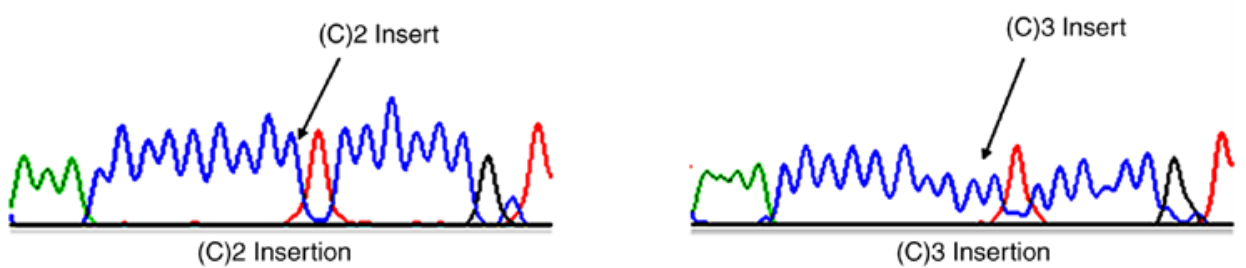

Figure 5. Formation of polynucleotide stretches. (A and B) The formation of polynucleotide C stretches. 


\section{C}

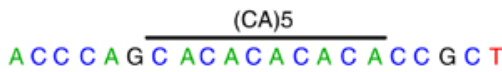

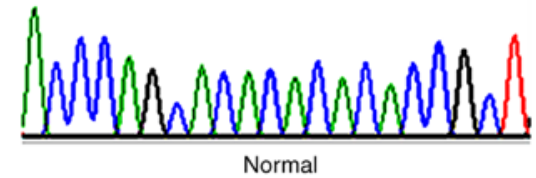

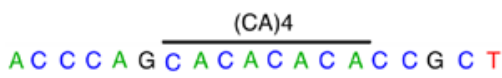

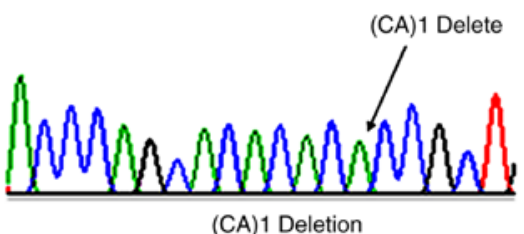

(CA)6 AC C CAG $\overline{C A C A C A C A C A C A}$ C GC T

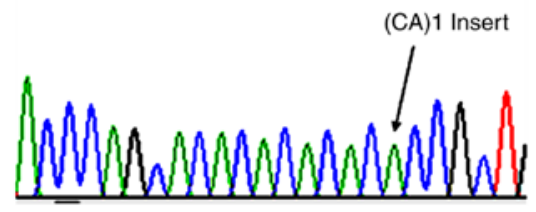

(CA)1 Insertion
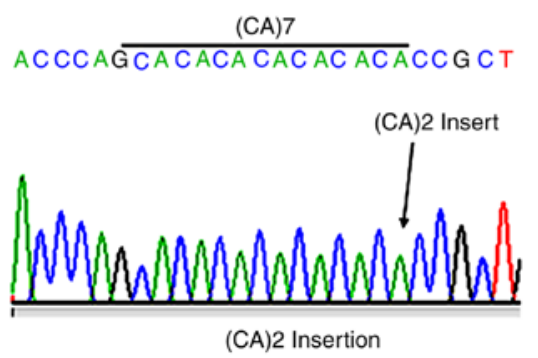

Figure 5. Continued. (C) Formation of repeated CA stretches. The letters in parentheses indicate the base type and the numbers following the parentheses indicate the number of bases.

occurrence of mtDNA D-loop mutations, but does not provide evidence of mtDNA deletions in Chinese patients with GIC; more severe mtDNA D-loop mutations may be identified in the advanced stages of GIC.

A previous study focused on the location of the tumorigenic mtDNA D-loop mutations, and identified carcinogenesis-specific nucleoside sites and poly-C variations (39). In addition, one study indicated that the np $16189 \mathrm{~T}-\mathrm{C}$ transition of the mtDNA D-loop may contribute to polyC instability in GC (19). Furthermore, another previous study reported that the minor haplotype of nucleotide $16290 \mathrm{~T}$ and the frequent haplotype of nucleotide $16298 \mathrm{~T}$ in the hypervariable segment 1 region were associated with a high survival rate of CRC, and the nucleotide site of 16290 was an independent predictor of CRC (40). However, a controversial opinion is that site-specific nucleotide mutations may result from mtDNA heterogeneity, and may not contribute to carcinogenesis and/or tumor progression (41). Thus, single nucleotide polymorphisms in the D-loop of mtDNA have been reported to be associated with an increased risk of $\mathrm{GC}$ and $\mathrm{CC}$, including the frequent alleles of $73 \mathrm{G} / \mathrm{A}, 146 \mathrm{~T} / \mathrm{C}, 195 \mathrm{~T} / \mathrm{C}, 324 \mathrm{C} / \mathrm{G}, 16261 \mathrm{C} / \mathrm{T}$ and $16304 \mathrm{~T} / \mathrm{C}$; additionally, the majority of mtDNA mutations are transitions (42-44). In the present study, the $\mathrm{T}-\mathrm{C}$ transition was the most common and clustered in specific areas in GIC; poly-C variations were evident in GIC.

It has been reported that mtMSI is a frequent occurrence in CRC (45), and mtDNA D-loop mutations and mtMSI appear to be associated with reactive oxygen species, apoptosis and proliferation in GC (46). To the best of our knowledge, no association has been identified between mtDNA mutations and mtMSI status, and no mtMSI-positive GC cases have exhibited large deletions in mtDNA (44). Furthermore, mtMSI appears to be particularly frequent at the D310 locus; however, the high prevalence of mtMSI was not associated with the prognosis of patients with CRC $(23,47)$. Notably, a previous study reported that stromal mtMSI may have possibly served an independent role in the pathogenesis of CC (48). In the present study, in addition to the poly- $\mathrm{C}$ stretch, a $\mathrm{CA}$ repeat sequence that was involved in GC-associated mtMSI may have been identified in GC.

\section{Acknowledgements}

Not applicable.

\section{Funding}

The present study was supported by grants from the National Natural Science Foundation of China (grant nos. 81571178, 81371399 and 81470098), the National Key R\&D Program of China (grant no. 2017YFC1201100), the Project of Construction of Innovative Teams and Teacher Career Development for Universities and Colleges Under Beijing Municipality (grant no. IDHT20150502), and the Project of Shandong Medical and Health Technology Development Plan (grant no. 2017WS835). 


\section{Availability of data and materials}

The datasets used and/or analyzed during the current study are available from the corresponding author on reasonable request.

\section{Authors' contributions}

BW collected the clinical data, analyzed the sequencing results and was a major contributor in writing the manuscript. LQ and JZ performed RT-qPCR. YW and DC conducted immunohistochemistry staining. $\mathrm{HG}$ and $\mathrm{YZ}$ assisted with the experiments and with writing the article. All authors read and approved the final manuscript.

\section{Ethics approval and consent to participate}

The present study was approved by the Ethics Committees of Shandong Cancer Hospital (Shandong, China). Written informed consent was obtained from all study participants.

\section{Patient consent for publication}

All patients agreed to the publication of their results and signed informed consents.

\section{Competing interests}

The authors declare that they have no competing interests.

\section{References}

1. Herszenyi L and Tulassay Z: Epidemiology of gastrointestinal and liver tumors. Eur Rev Med Pharmacol Sci 14: 249-258, 2010.

2. Zhu X and Li J: Gastric carcinoma in china: Current status and future perspectives (Review). Oncol Lett 1: 407-412, 2010.

3. Liu S, Zheng R, Zhang M, Zhang S, Sun X and Chen W: Incidence and mortality of colorectal cancer in China, 2011. Chin J Cancer Res 27: 22-28, 2015.

4. Chatterjee A, Dasgupta S and Sidransky D: Mitochondrial subversion in cancer. Cancer Prev Res 4: 638-654, 2011.

5. Damas J, Samuels DC, Carneiro J, Amorim A and Pereira F: Mitochondrial DNA rearrangements in health and disease-a comprehensive study. Hum Mutat 35: 1-14, 2014.

6. Yang Y, Yang X, Zhai F, et al: Dietary guidelines for chinese (2016). J Acad Nutr Dietetics 116: A37-A37, 2016.

7. Zhang Y, Wang M, Li H, Zhang H, Shi Y, Wei F, Liu D, Liu K and Chen D: Accumulation of nuclear and mitochondrial DNA damage in the frontal cortex cells of patients with HIV-associated neurocognitive disorders. Brain Res 1458: 1-11, 2012.

8. He L, Chinnery PF, Durham SE, Blakely EL, Wardell TM, Borthwick GM, Taylor RW and Turnbull DM: Detection and quantification of mitochondrial DNA deletions in individual cells by real-time PCR. Nucleic Acids Res 30: e68, 2002.

9. Krishnan KJ, Bender A, Taylor RW and Turnbull DM: A multiplex real-time PCR method to detect and quantify mitochondrial DNA deletions in individual cells. Anal Biochem 370: 127-129, 2007.

10. Perier C, Bender A, Garcia-Arumi E, Melià MJ, Bové J, Laub C, Klopstock T, Elstner M, Mounsey RB, Teismann P, et al: Accumulation of mitochondrial DNA deletions within dopaminergic neurons triggers neuroprotective mechanisms. Brain 136: 2369-2378, 2013.

11. Livak KJ and Schmittgen TD: Analysis of relative gene expression data using real-time quantitative PCR and the $2^{-\Delta \Delta C_{\mathrm{T}}}$ method. Methods 25: 402-408, 2001.

12. Zhang Y, Song F, Gao Z, Ding W, Qiao L, Yang S, Chen X, Jin $\mathrm{R}$ and Chen D: Long-term exposure of mice to nucleoside analogues disrupts mitochondrial DNA maintenance in cortical neurons. PLoS One 9: e85637, 2014.
13. Shi Y, Wang J, Wang Y, Wang A, Guo H, Wei F, Mehta SR, Espitia S, Smith DM, Liu L, et al: A novel mutant 10ala/arg together with mutant 144Ser/arg of hepatitis B virus X protein involved in hepatitis B virus-related hepatocarcinogenesis in HepG2 cell lines. Cancer Lett 371: 285-291, 2016.

14. Liu F, Yu DM, Huang SY, Yu JL, Zhang DH, Gong QM and Zhang XX: Clinical implications of evolutionary patterns of homologous, full-length hepatitis B virus quasispecies in different hosts after perinatal infection. J Clin Microbiol 52: 1556-1565, 2014

15. Ouyang Y, Liu L, Zhang Y, Yuan L, Liu Z, Yang S, Wei F, Qiao L and Chen D: Discordant patterns of tissue-specific genetic characteristics in the HIV-1 env gene from HIV-associated neurocognitive disorder (HAND) and non-HAND patients. J Neurovirol 20: 332-340, 2014.

16. Oberley TD: Oxidative damage and cancer. Am J Pathol 160: 403-408, 2002.

17. Boiteux S and Radicella JP: Base excision repair of 8-hydroxyguanine protects DNA from endogenous oxidative stress. Biochimie 81: 59-67, 1999.

18. Liang Q, Zeng J, Wu J, Qiao L, Chen Q, Chen D and Zhang Y: Nucleoside reverse transcriptase inhibitors induced hepatocellular mitochondrial DNA lesions and compensatory enhancement of mitochondrial function and DNA repair. Int J Antimicrob Agents 51: 385-392, 2018.

19. Han CB, Li F, Zhao YJ, Ma JM, Wu DY, Zhang YK and Xin Y: Variations of mitochondrial D-loop region plus downstream gene $12 \mathrm{~S}$ rRNA-tRNA ${ }^{\text {phe }}$ and gastric carcinomas. World $\mathrm{J}$ Gastroenterol 9: 1925-1929, 2003.

20. Lee HC, Li SH, Lin JC, Wu CC, Yeh DC and Wei YH: Somatic mutations in the D-loop and decrease in the copy number of mitochondrial DNA in human hepatocellular carcinoma. Mutat Res 547: 71-78, 2004.

21. Levy M, Visokai V, Lipska L and Topolcan O: Tumor markers in staging and prognosis of colorectal carcinoma. Neoplasma 55: $138-142,2008$.

22. Chatterjee A, Mambo E and Sidransky D: Mitochondrial DNA mutations in human cancer. Oncogene 25: 4663-4674, 2006.

23. Venderbosch S, van Vliet S, Craenmehr MH, Simmer F, de Haan AF, Punt CJ, Koopman $M$ and Nagtegaal ID: Mitochondrial microsatellite instability in patients with metastatic colorectal cancer. Virchows Archiv 466: 495-502, 2015.

24. Jeong CW, Lee JH, Sohn SS, Ryu SW and Kim DK: Mitochondrial microsatellite instability in gastric cancer and gastric epithelial dysplasia as a precancerous lesion. Cancer Epidemiol 34: 323-327, 2010.

25. Wallace DC: Mitochondria and cancer. Nat Rev Cancer 12: 685-698, 2012

26. Boland ML, Chourasia AH and Macleod KF: Mitochondrial dysfunction in cancer. Front Oncol 3: 292, 2013.

27. Webb E, Broderick P, Chandler I, Lubbe S, Penegar S, Tomlinson IP and Houlston RS: Comprehensive analysis of common mitochondrial DNA variants and colorectal cancer risk. Br J Cancer 99: 2088-2093, 2008.

28. Heerdt BG, Chen J, Stewart LR and Augenlicht LH: Polymorphisms, but lack of mutations or instability, in the promotor region of the mitochondrial genome in human colonic tumors. Cancer Res 54: 3912-3915, 1994.

29. Hibi K, Nakayama H, Yamazaki T, Takase T, Taguchi M, Kasai Y, Ito K, Akiyama S and Nakao A: Detection of mitochondrial DNA alterations in primary tumors and corresponding serum of colorectal cancer patients. Int J Cancer 94: 429-431, 2001.

30. Wu CW, Yin PH, Hung WY, Li AF, Li SH, Chi CW, Wei YH and Lee HC: Mitochondrial DNA mutations and mitochondrial DNA depletion in gastric cancer. Genes Chromosomes Cancer 44: 19-28, 2005.

31. Hung WY, Wu CW, Yin PH, Chang CJ, Li AF, Chi CW, Wei YH and Lee HC: Somatic mutations in mitochondrial genome and their potential roles in the progression of human gastric cancer. Biochim Biophys Acta 1800: 264-270, 2010.

32. Burgart LJ, Zheng J, Shu Q, Strickler JG and Shibata D: Somatic mitochondrial mutation in gastric cancer. Am J Pathol 147: 1105-1111, 1995.

33. Lievre A, Chapusot C, Bouvier AM, Zinzindohoué F, Piard F, Roignot P, Arnould L, Beaune P, Faivre J and Laurent-Puig P: Clinical value of mitochondrial mutations in colorectal cancer. J Clin Oncol 23: 3517-3525, 2005. 
34. Kassem AM,El-Guendy N, Tantawy M, Abdelhady H,El-Ghor A and Abdel Wahab AH: Mutational hotspots in the mitochondrial D-loop region of cancerous and precancerous colorectal lesions in egyptian patients. DNA Cell Biol 30: 899-906, 2011.

35. Ferreira A, Serafim TL, Sardao VA and Cunha-Oliveira T: Role of mtDNA-related mitoepigenetic phenomena in cancer. Eur J Clin Invest 1 (Suppl 45): S44-S49, 2015.

36. Iommarini L, Kurelac I, Capristo M, Calvaruso MA, Giorgio V, Bergamini C, Ghelli A, Nanni P, De Giovanni C, Carelli V, et al: Different mtDNA mutations modify tumor progression in dependence of the degree of respiratory complex I impairment. Hum Mol Genet 23: 1453-1466, 2014.

37. Berridge MV, Dong L and Neuzil J: Mitochondrial DNA in tumor initiation, progression, and metastasis: Role of horizontal mtDNA transfer. Cancer Res 75: 3203-3208, 2015.

38. Tamura G, Nishizuka S, Maesawa C, Suzuki Y, Iwaya T, Sakata K, Endoh Y and Motoyama T: Mutations in mitochondrial control region DNA in gastric tumours of Japanese patients. Eur J Cancer 35: 316-319, 1999.

39. Hung WY, Lin JC, Lee LM, Wu CW, Tseng LM, Yin PH, Chi CW and Lee HC: Tandem duplication/triplication correlated with poly-cytosine stretch variation in human mitochondrial DNA D-loop region. Mutagenesis 23: 137-142, 2008.

40. Wang C, Zhao S, Du Y and Guo Z: Single nucleotide polymorphisms in the D-loop region of mitochondrial DNA is associated with colorectal cancer outcome. Mitochondrial DNA A DNA Mapp Seq Anal 27: 4361-4363, 2016.

41. Yoneyama H, Hara T, Kato Y, Yamori T, Matsuura ET and Koike K: Nucleotide sequence variation is frequent in the mitochondrial DNA displacement loop region of individual human tumor cells. Mol Cancer Res 3: 14-20, 2005.
42. Guo Z, Zhao S, Fan H, Du Y, Zhao Y and Wang G: Identification of sequence polymorphisms in the D-Loop region of mitochondrial DNA as a risk factor for colon cancer. Mitochondrial DNA A DNA Mapp Seq Anal 27: 4244-4245, 2016.

43. Akouchekian M, Houshmand M, Hemati S, Ansaripour M and Shafa M: High rate of mutation in mitochondrial DNA displacement loop region in human colorectal cancer. Dis Colon Rectum 52: 526-530, 2009.

44. Maximo V, Soares P, Seruca R, Rocha AS, Castro P and Sobrinho-Simoes M: Microsatellite instability, mitochondrial DNA large deletions, and mitochondrial DNA mutations in gastric carcinoma. Genes Chromosomes Cancer 32: 136-143, 2001.

45. Habano W, Nakamura S and Sugai T: Microsatellite instability in the mitochondrial DNA of colorectal carcinomas: Evidence for mismatch repair systems in mitochondrial genome. Oncogene 17: 1931-1937, 1998.

46. Zhao YB, Yang HY, Zhang XW and Chen GY: Mutation in D-loop region of mitochondrial DNA in gastric cancer and its significance. World J Gastroenterol 11: 3304-3306, 2005.

47. Chang SC, Lin PC, Yang SH, Wang HS, Liang WY and Lin JK: Mitochondrial D-loop mutation is a common event in colorectal cancers with p53 mutations. Int J Colorectal Dis 24: 623-628, 2009.

48. Kim HS, Lim HS, Lee SH, Lee JW, Nam SW, Park WS, Lee YS, Lee JY and Yoo NJ: Mitochondrial microsatellite instability of colorectal cancer stroma. Int J Cancer 119: 2607-2611, 2006. 